nephron

Experimental

Nephrology

and Genetics
Nephron 2019;141:265-272

DOI: $10.1159 / 000496278$
Received: November 12, 2018

Accepted after revision: December 14, 2018

Published online: January 11, 2019

\title{
The Role of Renal Interstitial Cells in Proximal Tubular Regeneration
}

\author{
Hayo Castrop
}

Institute of Physiology, University of Regensburg, Regensburg, Germany

\section{Keywords}

Renal regeneration · Renal interstitial cells · Chronic kidney disease $\cdot$ Intravital imaging

\begin{abstract}
The healthy kidney is considered to be a relatively stable organ with little baseline cell turnover. Nevertheless, cells are constantly replaced to conserve the structural and functional integrity of the organ. The mechanisms of the baseline regenerative processes may also be relevant in situations of insults to the kidney, when the need for cellular replacement considerable exceeds the baseline cell turnover. This review will focus on the mechanisms of the regeneration of the tubular system, in particular the proximal tubule. Specifically, we will cover new aspects of (i), the regenerative capacity of the proximal tubule in health and disease, (ii) the relevant cell populations of proximal tubular regeneration, and (iii) the supportive role of renal interstitial cells in regenerative processes of the tubular system.
\end{abstract}

C 2019 S. Karger AG, Basel

\section{KARGER}

๑) 2019 S. Karger AG, Basel

E-Mail karger@karger.com

www.karger.com/nef

\section{Introduction}

Even in the absence of specific insults, the preservation of the structure and function of an organ requires the continuous replacement of decayed cells. In various organs, this baseline cell turnover differs markedly in terms of the number of cells being replaced at a given time. For example, in some organs, such as the skin, liver, and intestine, the baseline cell turnover is high, whereas in other organs such as the nervous system, the regenerative capacity is low. The kidneys belong to the latter group and are considered to be relatively stable organs $[1,2]$. In the human kidney approximately 70,000 epithelial cells of tubular origin are excreted in the urine per hour [3]. Given that presumably not all decayed cells of the tubular system appear in the urine, this means that at least 1.5 million tubular cells are lost during the course of 1 day. This translates into a loss of approximately 1 tubular cell per nephron and per day in humans. Similarly, a low baseline cell turnover has also been observed in rodents. In the rat kidney, less than $0.1 \%$ of all tubular cells are mitotic at a given time. Despite the replacement of decayed tubular 
cells in the healthy kidney, there is unambiguous evidence that the tubular system of the human kidney is subject to aging. The process of aging is characterized by a reduced maximum concentrating ability of the kidney and a delayed adaptation of renal salt excretion in response to changes in oral salt intake in elderly individuals [4-6]. This apparent decline in tubular function during aging may be caused by a specifically compromised function of the existing tubular cells and/or by an inadequate replacement of decayed cells with fully functional cells.

The baseline cell turnover is massively increased in situations of insults to the tubular system. An acute kidney injury (AKI) is considered largely reversible, given that the insult does not exceed a certain, poorly defined threshold. Based on the assessment of classical clinical parameters, such as glomerular filtration rate and albumin excretion, AKI is frequently reversed to a "normal" kidney function. Nevertheless, patients with post-AKI, in long-term, are at an increased risk of developing chronic kidney disease [7-10], suggesting that episodes of AKI increase the susceptibility of the tubular system to subsequent insults and/or that there is a chronic but clinically inapparent reduction in the function of the tubular epithelia upon regeneration. This may be related to the replacement of tubular cells by cells that are not fully functional.

The source of the substituting epithelial cells is still a matter of controversy. First, decayed tubular cells may be replaced by the proliferation, migration, and differentiation of epithelial cells in the vicinities of decayed cells [1113]. The nature of these cells will be discussed in detail. Second, some studies also suggest the existence of a stem cell niche in the renal inner medulla that consists of mesenchymal cells with the potential of integration and differentiation into tubular epithelial cells $[14,15]$. Third, there are reports indicating the immigration of extra-renal, bone marrow-derived progenitor cells into the kidney. These cells eventually contribute to the regeneration of decayed cells of the tubular system [16-20]. When considering all of the experimental attempts that have been made to identify the nature of the substituting epithelial cells, it appears that the majority of recent studies have suggested that the tubular epithelium is regenerated by cells of tubular origin.

Although probably not directly substituting for tubular epithelial cells, cells of the renal interstitium interact with the tubule and support its regeneration. In this context, recent data based on experiments using intravital multiphoton microscopy have shown that renal cortical interstitial cells are motile and migrate to the site of tubu- lar cell decay, wherein the interstitial cells support the regeneration of the epithelia after a tubular lesion [12]. This interaction between tubular and interstitial cells is based on multiple communication pathways between the tubular system and the interstitium that consist of paracrine factors and exosomes, which will be discussed in more detail below [12, 21-23].

\section{Which Cell Types Replace Decayed Tubular Cells?}

In principle, tubular cells may be replaced by cells of tubular and/or extra-tubular origin. Extra-tubular cells may be recruited from the renal interstitium and from extra-renal sources such as the bone-marrow (Fig. 1).

Tubular Epithelial Cells and Tubular Stem Cell-Like Precursor Cells

The contribution of tubular cells to tubular regeneration was assessed using genetic cell lineage tracing techniques in transgenic mice, in which most tubular epithelial cells were labeled with either beta-galactosidase (lac Z expression) or red fluorescent protein. Although extensive cell proliferation was observed after an ischemia-reperfusion injury (IRI), followed by the regeneration of the affected tubules, no dilution of the transgenic markers was reported, thus suggesting that there is no integration of extra-tubular cells during repair [11]. Similar results were obtained using intravital imaging of the healthy mouse kidney. When GFP was expressed specifically in the tubular system by the use of the Pax 8 promoter, no un-stained cells appeared in the region of a local epithelial lesion that was caused by a high-power laser exposure [12]. Using the same method in mice that were expressing red fluorescent protein under the control of the platelet-derived growth factor $\beta$ (PDGFR $\beta$ ) promoter, no red cells where found in the proximal tubule, thus suggesting again that cells from outside of the tubule do not integrate into the tubular epithelium to a considerable extent.

Although there is convincing evidence for the replacement of tubular cells by cells of a tubular origin, it is still an ongoing debate as to whether the substituting cells are surviving differentiated tubular cells or, rather, they are a subpopulation of specialized progenitor/stem cells.

A recent study in mice that used a double DNA analogue incorporation strategy to follow sequential rounds of DNA synthesis in dividing cells showed that tubular cell replacement, in response to IRI, was randomly mediated by the division of the surviving cells [24]. There were no apparent hot spots of cell division within the tubular epithelium, which suggests that any surviving 


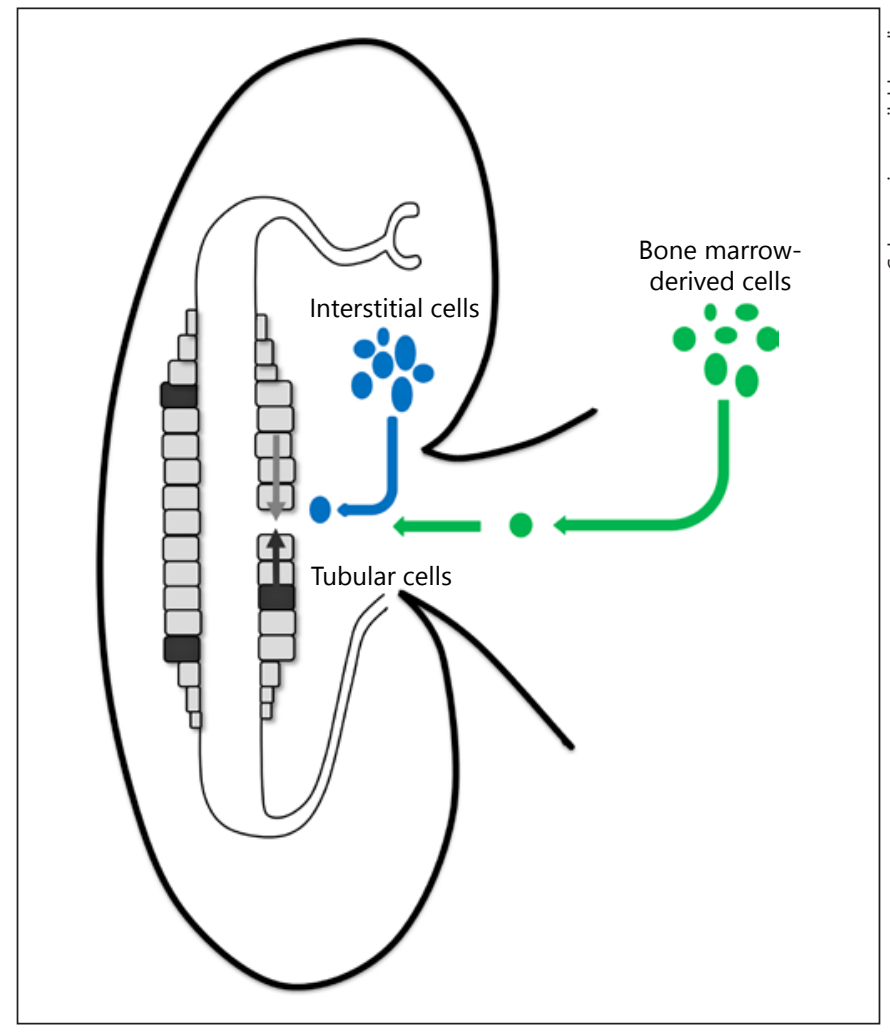

Fig. 1. In the healthy kidney, epithelial cells of the tubular system are constantly lost to a small extent. There is experimental evidence for 3 potential pathways, along which decayed tubular cells are replaced. (1) Tubular cells are replaced by tubular cells in the vicinities of the lost cell. These cells may be normal surviving cells and/or specialized progenitor cells (depicted as dark cells). (2) Tubular cells are replaced by interstitial cells, which integrate into the tubular epithelium and/or migrate to the site of tubular cell loss in order to support the tubular regeneration by the release of paracrine factors. (3) Extra-renal, bone marrow-derived cells migrate into the kidney along unknown pathways and, eventually, integrate into the tubular epithelium in order to differentiate into functional tubular cells. Alternatively, bone marrow-derived cells may support the tubular regeneration by the generation of paracrine factors, rather than integrating into the tubular epithelium.

cell may be involved in the regeneration of the tubule, rather than indicating that regeneration is due to the existence of specialized cells with increased mitotic potentials $[24,25]$. A recent study, however, provided evidence that normal surviving tubular epithelial cells may not divide but rather contribute to the survival of the epithelium by endocycle-related cellular hypertrophy [26]. These results, however, were partly challenged by a report suggesting that sub-lethally injured tubular cells proliferate after IRI injury and that tubular proliferation crucially depends on the expression of the transcription factor FoxM1 [27]. Similarly, intravital imaging experiments that examined proximal tubular cell division and migration tracking, in combination with subsequent ex vivo histological analysis, demonstrated a sequence of dedifferentiation (de novo expression of the dedifferentiation marker CD44, loss of megalin expression and loss of the apical brush boarder), cell division, and migration to the site of tubular cell decay, and, eventually, a sequence of redifferentiation (expression of megalin, brush boarder formation, functional albumin uptake, and the loss of CD44 expression) [12] (Fig. 2). It should be noted that in contrast to the previously mentioned investigations of renal IRI, this study addressed the replacement of single tubular cells in the healthy kidney, which is a situation similar to what is expected during normal aging.

In contrast to the assumption that any surviving tubular cells may contribute to the regeneration of the tubular epithelium, there is evidence suggesting the existence of progenitor cells in the adult human kidney; in particular, progenitor cells that are located in the urinary aspect of Bowman's capsule. These cells are characterized by the expression of CD133 and CD24 and differentiate into podocytes and the cells of the early proximal tubule [2830]. Consequently, it appears reasonable to assume that progenitor cells may also reside in other portions of the tubular system [31]. In fact, scattered CD133+/CD24+/ CD106- cells were found to be localized to both the proximal tubule and the distal convoluted tubule of the human kidney. These cells were characterized by an increased survival, compared with the survival of neighboring cells, during AKI $[32,33]$. Even more importantly, when injected in immune-deficient mice, these cells generated functional tubular cells and improved kidney function, thus suggesting that they are tubular progenitor cells [32]. In contrast to the results of this study, genetic cell fate tracing in mice suggested that the scattered progenitor cells observed in the human kidney do not represent a specific population and that any proximal tubular cell participates in the repair process after injury $[13,25]$. Species differences and the specific injury model may be relevant variables of the mechanism of renal tubular regeneration and may contribute to the observed conflicting results.

Stem Cells in the Renal Papilla

In addition to the debated tubular stem cells, there is experimental evidence that supports the existence of stem cells in the interstitium of the renal papilla $[14,15]$. Thus, in order to detect cells with a low cycling rate in 


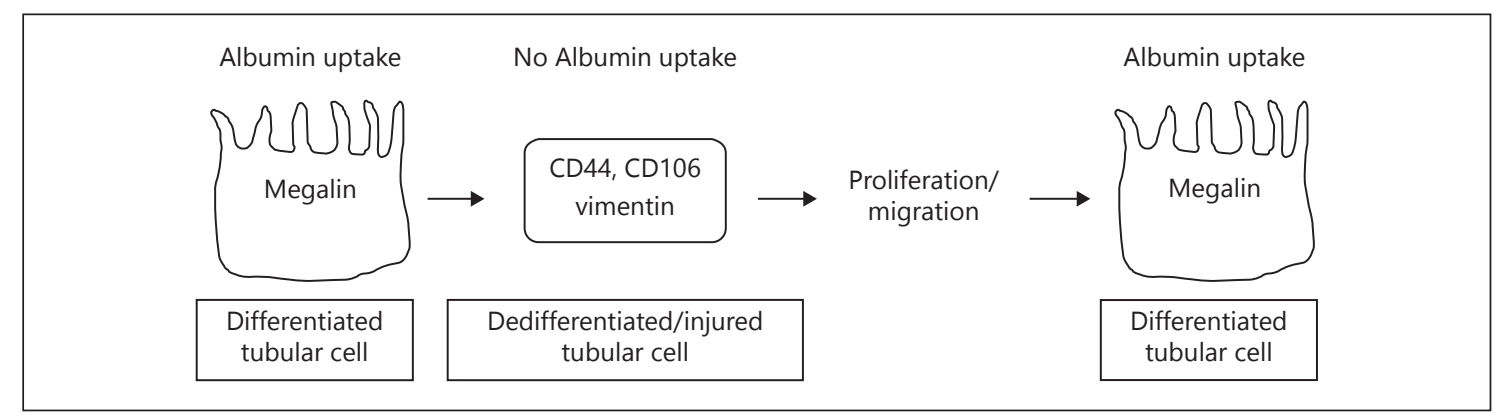

Fig. 2. The course of events during the replacement of tubular epithelial cells by surviving tubular cells, as determined by the use of serial intravital multiphoton microscopy in combination with ex vivo immunohistochemistry. Differentiated tubular cells in the vicinity of decayed tubular cells dedifferentiate (loss of the expression of megalin, morphological changes to a flat cubical phenotype with no brush boarder) initiate the expression of CD44, CD106,

the kidney, a pulse of bromodeoxyuridine (BrdU) was given to mouse and rat pups [15]. After several months of a pulse-chase analysis, BrdU-retaining cells were identified. BrdU-retaining cells were localized predominantly in the renal papilla and entered the cell cycle in response to IRI. Moreover, the proliferation of these cells was accompanied by the migration to the upper portions of the papilla. Based on the cycling behavior of the cells in the kidney, along with the formation of spheres and the ability of the cells to differentiate into different cell types in vitro, the authors suggested the identification of a renal stem cell niche. Most notably, a few labeled cells became incorporated into the renal tubules suggesting that the decayed epithelial cells were being replaced by papillary stem cells [15]. These results were intensely debated, and it was suggested that the population of low cycling cells in the renal papillary interstitium may correspond to cells that exit the cell cycle early in kidney development, rather than representing a specific population of adult stem cells [34]. In fact, when compared with the ongoing organogenesis in the cortex, the renal papilla matures early during development. Furthermore, label-containing cells within the tubular epithelium may represent cell fusion events, rather than representing an integration of stem cells into the epithelium [35]. Nevertheless, in an independent study, the expression of the enzyme telomerase reverse transcriptase, a key enzyme associated with embryonic and some adult stem cells, was detected in the renal papilla, including in the inner medullary collecting duct [13]. However, these cells did not proliferate in response to IRI and were not directly involved in tissue regeneration [13]. A potential role of and vimentin. The cells lose the ability of albumin internalization. Subsequently, these cells proliferate and migrate to the site of tubular cell loss. Eventually, the cells redifferentiate and lose the markers CD44, CD106, and vimentin. The morphological changes are accompanied by the regained albumin uptake capacity (up to $80 \%$ of albumin uptake capacity of normal tubular epithelial cells; from [11]).

low-cycling cells of the renal papilla in the baseline cell turnover in the healthy kidney awaits further systematic investigation.

Role of Extra-Renal Cells in Tubular Regeneration

The regenerative contribution of extra-renal cells that immigrate into the kidney has also been reported for various renal injury models. Thus, bone marrow-derived cells of unspecified lineages were shown to populate the kidney and may contribute to the regeneration of tubular epithelia and various cell types of the glomerulus, including mesangial cells and podocytes [16-20]. However, bone marrow-derived cells do not survive in the kidney for prolonged periods of time, and the number of these cells within the kidney declines rapidly [36]. Furthermore, markers of bone marrow-derived cells may appear in the tubular epithelium by means of cell fusion events $[35,37]$. From these data, it appears likely that bone marrow-derived cells serve as modulators of intrinsic renal regenerative programs, rather than undergoing differentiation into functional renal cells. It has been speculated that these cells locally generate cytokines that may support dedifferentiation, mitosis, migration, and differentiation during the course of the replacement of tubular cells $[38,39]$. The role of bone marrow-derived cells in the maintenance of the integrity of the tubular epithelia in the healthy kidney has not been experimentally addressed. Similarly, the pathways along which marrowderived cells enter the kidney remain to be elucidated.

In summary, several genetic lineage studies have strongly suggested that new tubular epithelial cells are derived from epithelial cells and that an integration of inter- 
stitial cells into the tubular epithelium is an unlikely event, although bone marrow-derived cells may make a limited contribution.

\section{Are New Tubular Cells Fully Functional? The Key to Renal Aging}

During normal aging, the functional capacity of the tubular system declines. In elderly humans, the maximum concentrating ability of the kidney is reduced, and the adaptation of salt reabsorption processes, in response to changes in oral salt intake, is delayed [4-6]. The cellular correlates to the functional impairments may be dual: the number of functional tubular cells may decline during aging because not every decayed cell is replaced by a new tubular cell; alternatively, new tubular cells may not be fully differentiated in terms of reabsorptive function. For the latter possibility, we initially found evidence when we assessed the function of newly generated cells of the proximal tubule [12]. These cells had replaced single tubular cells, which were ablated by laser exposure in the health kidney. New tubular cells gained the typical features of the proximal tubule, such as a pronounced brush border, as well as the expressions of megalin and sodium-hydrogen exchanger 3 . They also regained proximal tubular functional capacity, as determined by the uptake of labeled albumin. Nevertheless, through the use of intravital multiphoton imaging, we found that the albumin uptake capacity of the new tubular cells markedly increased over a few days, but it never exceeded $80 \%$ of the capacity of neighboring epithelial cells, even after 5 weeks of followup [12]. Consequently, the dedifferentiation, cell division, and migration to the site of injury may have limited the functional capacity of the new tubular cells.

\section{The Role of Interstitial Cells in the Control of Tubular Regeneration}

There is evidence for the presence of a mesenchymal stem cell niche in the renal papilla, as outlined in detail above. However, for the renal cortex, little is known about the role of interstitial cells in tubular cell turnover. Similarly to other organs, such as the skin, renal cortical interstitial cells may support the regeneration of the tubular epithelium, for example, through the release of paracrine pro-regenerative factors. In this case, the interstitial cells would not integrate into the tubular epithelium. Furthermore, interstitial cells may mechanically support the structure of the tubule [12].

The interstitium of the renal cortex is composed of various cell populations, including fibroblast-like cells, pericytes, and immune cells. More than $90 \%$ of all inter-

The Role of Renal Interstitial Cells in

Proximal Tubular Regeneration stitial cells in the renal cortex express the PDGFR $\beta$ $[40,41]$. A subpopulation of cortical interstitial cells produces erythropoietin and is further characterized by the expression of CD73 [42]. Otherwise, relatively little is known about other functions of the renal cortical interstitium in the healthy kidney. In contrast to the role of renal cortical interstitial cells in normal physiology, there is ample evidence to support the concept that resident interstitial cells contribute to the generation of interstitial fibrosis during chronic insults to the kidney. In a recent study, the contribution of resident interstitial fibroblasts to the overall collagen I deposition in interstitial fibrosis has been estimated to be in the range of $50-60 \%$, with the remaining collagen I deposition being generated by immigrating hematopoietic cells [43].

\section{Tubular-Interstitial Crosstalk during Tubular Epithelial Regeneration}

In response to insults to the tubular system, communication pathways between the epithelial and mesenchymal cell of the interstitium have been established that predominantly lead to an activation of interstitial cells. Although potentially reno-protective in the short-term, a continuous activation of interstitial cells leads to the formation of excess extracellular matrix, and, consequently, to renal interstitial fibrosis. The signaling between diseased tubular cells and the interstitium consists of paracrine factors released by the tubular epithelium. These factors include the transforming growth factor- $\beta_{1}$ (TGF- $\beta_{1}$ ), which activates type II/I TGF- $\beta$ receptor complexes located on the interstitial mesenchymal cell. As downstream targets, Smad2 and Smad3 are phosphorylated, and they are translocated to the nucleus, in order to induce target genes, including components of the extracellular matrix (for a comprehensive review see [44]). In addition to the unidirectional signaling via TGF- $\beta_{1}$, signaling between the tubular epithelium and the interstitial cells may also be bidirectional. For example, the $\mathrm{Wnt} / \beta$-catenin-dependent signaling pathway involves the expression of Wnt by activated interstitial fibroblasts, which leads to the increased stabilization of $\beta$-catenin in tubular epithelial cells and subsequent cell cycle progression, in order to replace the decayed tubular cells [44]. The Wnt pathways, in turn, are activated by Dickkopf 3, which is released by injured tubular epithelia whereas it is largely absent from intact tubular cells [45]. Furthermore, Gli1-positive pericytes, a subset of interstitial cells with stem cell-like properties, appear to be relevant for the maintenance of the structure and function of the tubular epithelia [46]. Thus, genetic abla- 
tion of Gli1-positive pericytes caused transient tubular injury and the development of mild interstitial fibrosis [46].

If the tubular injury is fully resolved, matrix metalloproteinase- 7 is secreted from the tubule and causes the apoptosis of proliferated interstitial cells in the vicinity of the affected tubule [47]. In this context, a recent study using the targeted expression of the Diphtheria receptor in the proximal tubule revealed that locally limited insults to the proximal tubule may fully resolve, whereas repeated injuries cause irreversible capillary loss and interstitial fibrosis [48].

Additional paracrine factors are involved in the subtle communication between the tubular epithelium and the interstitial fibroblasts, including hepatocyte growth factor ([49]) and connective tissue growth factor ([50]). In addition to paracrine soluble factors, exosomes that are released from injured tubules can transport signaling molecules to the fibroblasts, which then respond with proliferation and extracellular matrix generation [21].

In the healthy kidney, the decay and replacement of single tubular cells is a rare event. Consequently, tubular regeneration has been predominantly investigated in disease models of the tubular system, rather than during the aging of the healthy kidney. The use of serial intravital imaging, however, has markedly expanded our possibilities, thus allowing researchers to address structural and functional changes over prolonged periods of time in the same animal $[12,51,52]$. For example, the excitation laser used for multiphoton intravital microscopy can be employed as a tool to ablate single tubular cells via focused, high energy laser exposure in an otherwise healthy kidney. Although it is not possible to exclude some limited impact on adjacent cells in the immediate vicinity of the laser impact, this model largely mimics the loss of single tubular cells in the otherwise healthy kidney. Using this approach, we recently found that the decay of single proximal tubular cells consistently induced a calcium wave that originated at the site of injury and subsequently spread into the interstitium [12]. The increase in calcium initiated the targeted migration of PDGFR $\beta$ positive interstitial cells to the site of tubular cell loss. In the migrating interstitial cells, the intracellular calcium concentration remained elevated for several days. The average velocity of the migration of the PDGFR $\beta$ fibroblasts was in the range of $1.6 \pm 0.2 \mu \mathrm{m} / \mathrm{h}$ within the first $24 \mathrm{~h}$. Within $48 \mathrm{~h}, \mathrm{PDGFR} \beta$-positive interstitial cells had wrapped around the tubule and had enclosed the site of tubular cell ablation. After 7 days, PDGFR $\beta$-positive interstitial cells had moved away from the site of injury and had dispersed into the interstitium. The withdrawal of the interstitial cells from the tubule after 7 days coincided with the structural and functional recovery of the affected tubule [12].

The mechanism of the targeted migration of PDGFR $\beta$ positive interstitial cells to the site of tubular cell loss involves the activation of the PDGFR $\beta$ receptor on interstitial cells. Thus, in the presence of the PDGFR antagonist trapidil, the calcium response and the migration of interstitial cells were markedly reduced. Furthermore, the functional recovery of the affected tubule was compromised when rats were administered trapidil, thus suggesting that the interaction of interstitial cells with the tubule is a crucial prerequisite for the process of the replacement of the decayed tubular cells and the subsequent recovery of tubular function [12].

According to these data, the PDGF-BB/PDGFR $\beta$ axis is crucial for the replacement of single tubular cells in the healthy kidney, but it also appears to be relevant in the recovery from global acute kidney diseases. Thus, trapidil application impaired the tubular regeneration after ischemia-reperfusion in rats [22]. As there is no evidence for the expression of PDGF receptors in the proximal tubule $[12,23]$, it appears likely that the activation of PDGFR $\beta$ on interstitial cells accounts for the pro-regenerative function of the activation of the PDGF-BB/ PDGFR $\beta$ axis. PDGF-BB is expressed in immature tubules during nephrogenesis [53], and PDGF-BB expression is reactivated during kidney disease [41]. Accordingly, we found a marked induction of PDGF-BB expression in the vicinities of single ablated cells of the proximal tubule, suggesting that the source of PDGF-B-dependent chemotaxis of interstitial cells is a tubular one. Alternatively, PDGF-BB may leak from the tubular lumen into the interstitium upon injuries to the integrity of the epithelial barrier. With a molecular weight of approximately $24 \mathrm{kDa}$, PDGF-BB is expected to be virtually freely filtered. According to this concept, the source of PDGF- BB would cease once the integrity of the proximal tubule is reestablished, and, consequently, the chemotactic stimulus for the migration of interstitial cells is no longer present. To date, this hypothesis awaits experimental evaluation.

\section{The PDGF-BB/PDGFR $\beta$ Axis: Beneficial}

\section{or Problematic}

Whatever source eventually proves to be relevant for the chemotactic migration of interstitial cells to the sight of tubular epithelial cell decay, the overall effect of the activation of the PDGF-BB/PDGFR $\beta$ axis in this context 
appears to be beneficial, as it is supportive of tubular regeneration. During global injuries to the kidney, however, PDGF-BB/PDGFR $\beta$ signaling may initiate fibrosis and scarring, thus resulting in an accelerated progression of renal disease. In this situation, the regeneration of the tubular epithelium may be incomplete, and the PDGF-BB/PDGFR $\beta$ axis may be chronically activated, thus resulting in the development of renal interstitial fibrosis [54]. For example, specific PDGF antagonism via the treatment with an oligonucleotide aptamer attenuated the progression of mesangioproliferative glomerulonephritis in rats [55]. When treated with the PDGF-B aptamer, the long-term deterioration of kidney function was largely blocked, and several parameters of kidney function and structure, such as glomerular filtration rate, albuminuria, extracellular matrix formation, and macrophage influx, were markedly improved [55]. In line with these results, repeated injections of PDGF-BB in rats for 1 week caused interstitial cell proliferation and the development of interstitial fibrosis [56]. The longterm effects of the pharmacological inhibition of the PDGF-BB/PDGFR $\beta$ axis on renal aging remain to be determined.

In summary, the replacement of decayed cells of the tubular system appears to require a balanced cooperation between the tubular epithelial and interstitial cells. Based on recent data, it is reasonable to hypothesize that interstitial cells support the regeneration of the tubule, but, presumably do not incorporate into the epithelium. Though beneficial for the preservation of the structure and function of the tubules of the healthy kidney, an overshooting activation of the renal interstitial cells in kidney disease may induce the formation of fibrosis, with a longterm chronic deterioration of kidney function.

\section{Disclosure Statement}

The author has no conflicts of interest to declare.

\section{References}

1 Ledda-Columbano GM, Columbano A, Coni P, Curto M, Faa G, Pani P: Cell proliferation in rat kidney induced by 1,2-dibromoethane. Toxicol Lett 1987;37:85-90.

2 Messier B, Leblond CP: Cell proliferation and migration as revealed by radioautography after injection of thymidine-h3 into male rats and mice. Am J Anat 1960;106:247-285.

3 Prescott LF: The normal urinary excretion rates of renal tubular cells, leucocytes and red blood cells. Clin Sci 1966;31:425-435.

4 Sands JM: Urine concentrating and diluting ability during aging. J Gerontol A Biol Sci Med Sci 2012;67:1352-1357.

5 Rowe JW, Shock NW, DeFronzo RA: The influence of age on the renal response to water deprivation in man. Nephron 1976;17:270278.

6 O'Neill PA, McLean KA: Water homeostasis and ageing. Med Lab Sci 1992;49:291-298.

7 James MT, Hemmelgarn BR, Wiebe N, Pannu N, Manns BJ, Klarenbach SW, Tonelli M; Alberta Kidney Disease Network: Glomerular filtration rate, proteinuria, and the incidence and consequences of acute kidney injury: a cohort study. Lancet 2010;376:2096-2103.

8 James MT, Ghali WA, Tonelli M, Faris P, Knudtson ML, Pannu N, Klarenbach SW, Manns BJ, Hemmelgarn BR: Acute kidney injury following coronary angiography is associated with a long-term decline in kidney function. Kidney Int 2010;78:803-809.

9 Coca SG, Singanamala S, Parikh CR: Chronic kidney disease after acute kidney injury: a systematic review and meta-analysis. Kidney Int 2012;81:442-448.
10 Rydén L, Sartipy U, Evans M, Holzmann MJ: Acute kidney injury after coronary artery bypass grafting and long-term risk of end-stage renal disease. Circulation 2014;130:20052011.

11 Humphreys BD, Valerius MT, Kobayashi A, Mugford JW, Soeung S, Duffield JS, McMahon AP, Bonventre JV: Intrinsic epithelial cells repair the kidney after injury. Cell Stem Cell 2008;2:284-291.

12 Schiessl IM, Grill A, Fremter K, Steppan D, Hellmuth MK, Castrop H: Renal interstitial platelet-derived growth factor receptor- $\beta$ cells support proximal tubular regeneration. J Am Soc Nephrol 2018;29:1383-1396.

13 Song J, Czerniak S, Wang T, Ying W, Carlone DL, Breault DT, Humphreys BD: Characterization and fate of telomerase-expressing epithelia during kidney repair. J Am Soc Nephrol 2011;22:2256-2265.

14 Oliver JA, Klinakis A, Cheema FH, Friedlander J, Sampogna RV, Martens TP, Liu C, Efstratiadis A, Al-Awqati Q: Proliferation and migration of label-retaining cells of the kidney papilla. J Am Soc Nephrol 2009;20:23152327.

15 Oliver JA, Maarouf O, Cheema FH, Martens TP, Al-Awqati Q: The renal papilla is a niche for adult kidney stem cells. J Clin Invest 2004; 114:795-804.

16 Gupta S, Verfaillie C, Chmielewski D, Kim Y, Rosenberg ME: A role for extrarenal cells in the regeneration following acute renal failure. Kidney Int 2002;62:1285-1290.

17 Kunter U, Rong S, Boor P, Eitner F, MüllerNewen G, Djuric Z, van Roeyen CR, Koniec- zny A, Ostendorf T, Villa L, MilovancevaPopovska M, Kerjaschki D, Floege J: Mesenchymal stem cells prevent progressive experimental renal failure but maldifferentiate into glomerular adipocytes. J Am Soc Nephrol 2007;18:1754-1764.

18 Poulsom R, Forbes SJ, Hodivala-Dilke K, Ryan E, Wyles S, Navaratnarasah S, Jeffery R, Hunt T, Alison M, Cook T, Pusey C, Wright NA: Bone marrow contributes to renal parenchymal turnover and regeneration. J Pathol 2001;195:229-235.

19 Prodromidi EI, Poulsom R, Jeffery R, Roufosse CA, Pollard PJ, Pusey CD, Cook HT: Bone marrow-derived cells contribute to podocyte regeneration and amelioration of renal disease in a mouse model of alport syndrome. Stem Cells 2006;24:2448-2455.

20 Sugimoto $\mathrm{H}$, Mundel TM, Sund M, Xie L, Cosgrove D, Kalluri R: Bone-marrow-derived stem cells repair basement membrane collagen defects and reverse genetic kidney disease. Proc Natl Acad Sci U S A 2006;103: 7321-7326.

21 Borges FT, Melo SA, Özdemir BC, Kato N, Revuelta I, Miller CA, Gattone VH 2nd, LeBleu VS, Kalluri R: TGF- $\beta 1$-containing exosomes from injured epithelial cells activate fibroblasts to initiate tissue regenerative responses and fibrosis. J Am Soc Nephrol 2013; 24:385-392.

22 Nakagawa T, Sasahara M, Haneda M, Kataoka H, Nakagawa H, Yagi M, Kikkawa R, Hazama F: Role of PDGF B-chain and PDGF receptors in rat tubular regeneration after acute injury. Am J Pathol 1999;155:1689-1699.
The Role of Renal Interstitial Cells in Proximal Tubular Regeneration
Nephron 2019;141:265-272 DOI: $10.1159 / 000496278$ 
23 Seifert RA, Alpers CE, Bowen-Pope DF: Expression of platelet-derived growth factor and its receptors in the developing and adult mouse kidney. Kidney Int 1998;54:731-746.

24 Humphreys BD, Czerniak S, DiRocco DP, Hasnain W, Cheema R, Bonventre JV: Repair of injured proximal tubule does not involve specialized progenitors. Proc Natl Acad Sci U S A 2011;108:9226-9231.

25 Berger K, Bangen JM, Hammerich L, Liedtke C, Floege J, Smeets B, Moeller MJ: Origin of regenerating tubular cells after acute kidney injury. Proc Natl Acad Sci U S A 2014;111: 1533-1538.

26 Lazzeri E, Angelotti ML, Peired A, Conte C, Marschner JA, Maggi L, Mazzinghi B, Lombardi D, Melica ME, Nardi S, Ronconi E, Sisti A, Antonelli G, Becherucci F, De Chiara L, Guevara RR, Burger A, Schaefer B, Annunziato F, Anders HJ, Lasagni L, Romagnani P: Endocycle-related tubular cell hypertrophy and progenitor proliferation recover renal function after acute kidney injury. Nat Commun 2018;9:1344.

27 Chang-Panesso M, Kadyrov FF, Lalli M, Wu H, Ikeda S, Kobayashi A, Humphreys BD: Foxm1 drives proximal tubule proliferation during repair from acute kidney injury. BioRxiv 2018.

28 Ronconi E, Sagrinati C, Angelotti ML, Lazzeri E, Mazzinghi B, Ballerini L, Parente E, Becherucci F, Gacci M, Carini M, Maggi E, Serio M, Vannelli GB, Lasagni L, Romagnani S, Romagnani P: Regeneration of glomerular podocytes by human renal progenitors. J Am Soc Nephrol 2009;20:322-332.

29 Sagrinati C, Netti GS, Mazzinghi B, Lazzeri E, Liotta F, Frosali F, Ronconi E, Meini C, Gacci M, Squecco R, Carini M, Gesualdo L, Francini F, Maggi E, Annunziato F, Lasagni L, Serio M, Romagnani S, Romagnani P: Isolation and characterization of multipotent progenitor cells from the bowman's capsule of adult human kidneys. J Am Soc Nephrol 2006;17: 2443-2456.

30 Appel D, Kershaw DB, Smeets B, Yuan G, Fuss A, Frye B, Elger M, Kriz W, Floege J, Moeller MJ: Recruitment of podocytes from glomerular parietal epithelial cells. J Am Soc Nephrol 2009;20:333-343.

31 Lindgren D, Boström AK, Nilsson K, Hansson J, Sjölund J, Möller C, Jirström K, Nilsson E, Landberg G, Axelson H, Johansson ME: Isolation and characterization of progenitorlike cells from human renal proximal tubules. Am J Pathol 2011;178:828-837.

32 Angelotti ML, Ronconi E, Ballerini L, Peired A, Mazzinghi B, Sagrinati C, Parente E, Gacci M, Carini M, Rotondi M, Fogo AB, Lazzeri E, Lasagni L, Romagnani P: Characterization of renal progenitors committed toward tubular lineage and their regenerative potential in renal tubular injury. Stem Cells 2012;30:17141725 .
33 Hansson J, Hultenby K, Cramnert C, Pontén F, Jansson H, Lindgren D, Axelson H, Johansson ME: Evidence for a morphologically distinct and functionally robust cell type in the proximal tubules of human kidney. Hum Pathol 2014;45:382-393.

34 Adams DC, Oxburgh L: The long-term label retaining population of the renal papilla arises through divergent regional growth of the kidney. Am J Physiol Renal Physiol 2009; 297:F809-F815.

35 Terada N, Hamazaki T, Oka M, Hoki M, Mastalerz DM, Nakano Y, Meyer EM, Morel L, Petersen BE, Scott EW: Bone marrow cells adopt the phenotype of other cells by spontaneous cell fusion. Nature 2002;416:542-545.

36 Duffield JS, Park KM, Hsiao LL, Kelley VR, Scadden DT, Ichimura T, Bonventre JV: Restoration of tubular epithelial cells during repair of the postischemic kidney occurs independently of bone marrow-derived stem cells. J Clin Invest 2005;115:1743-1755.

37 Rizvi AZ, Swain JR, Davies PS, Bailey AS, Decker AD, Willenbring $H$, Grompe $M$, Fleming $\mathrm{WH}$, Wong $\mathrm{MH}$ : Bone marrow-derived cells fuse with normal and transformed intestinal stem cells. Proc Natl Acad Sci U S A 2006;103:6321-6325.

38 Imberti B, Morigi M, Tomasoni S, Rota C, Corna D, Longaretti L, Rottoli D, Valsecchi F, Benigni A, Wang J, Abbate M, Zoja C, Remuzzi G: Insulin-like growth factor-1 sustains stem cell mediated renal repair. J Am Soc Nephrol 2007;18:2921-2928.

39 Tögel F, Zhang P, Hu Z, Westenfelder C: VEGF is a mediator of the renoprotective effects of multipotent marrow stromal cells in acute kidney injury. J Cell Mol Med 2009;13: 2109-2114.

40 Gerl K, Nolan KA, Karger C, Fuchs M, Wenger RH, Stolt CC, Willam C, Kurtz A, Kurt B: Erythropoietin production by PDGFR- $\beta(+)$ cells. Pflugers Arch 2016;468: 1479-1487.

41 Boor P, Ostendorf T, Floege J: Pdgf and the progression of renal disease. Nephrol Dial Transplant 2014;29(suppl 1):i45-i54.

42 Le Hir M, Kaissling B: Distribution and regulation of renal ecto-5'-nucleotidase: Implications for physiological functions of adenosine. Am J Physiol 1993;264(3 pt 2):F377F387.

43 Buchtler S, Grill A, Hofmarksrichter S, Stöckert P, Schiechl-Brachner G, Rodriguez Gomez M, Neumayer S, Schmidbauer K, Talke Y, Klinkhammer BM, Boor P, Medvinsky A, Renner K, Castrop H, Mack M: Cellular origin and functional relevance of collagen I production in the kidney. J Am Soc Nephrol 2018;29: 1859-1873.

44 Tan RJ, Zhou D, Liu Y: Signaling crosstalk between tubular epithelial cells and interstitial fibroblasts after kidney injury. Kidney Dis (Basel) 2016;2:136-144.
45 Gröne EF, Federico G, Nelson PJ, Arnold B, Gröne HJ: The hormetic functions of wnt pathways in tubular injury. Pflugers Arch 2017;469:899-906.

46 Kramann R, Wongboonsin J, Chang-Panesso M, Machado FG, Humphreys BD: Gli1 ${ }^{+}$pericyte loss induces capillary rarefaction and proximal tubular injury. J Am Soc Nephrol 2017;28:776-784.

47 He W, Tan RJ, Li Y, Wang D, Nie J, Hou FF, Liu Y: Matrix metalloproteinase-7 as a surrogate marker predicts renal wnt $/ \beta$-catenin activity in CKD. J Am Soc Nephrol 2012;23: 294-304.

48 Grgic I, Campanholle G, Bijol V, Wang C, Sabbisetti VS, Ichimura T, Humphreys BD, Bonventre JV: Targeted proximal tubule injury triggers interstitial fibrosis and glomerulosclerosis. Kidney Int 2012;82:172-183.

49 Fabian SL, Penchev RR, St-Jacques B, Rao AN, Sipilä P, West KA, McMahon AP, Humphreys BD: Hedgehog-Gli pathway activation during kidney fibrosis. Am J Pathol 2012;180: 1441-1453.

50 Yang F, Chung AC, Huang XR, Lan HY: Angiotensin II induces connective tissue growth factor and collagen I expression via transforming growth factor-beta-dependent and -independent Smad pathways: the role of Smad3. Hypertension 2009;54:877-884.

51 Schießl IM, Hammer A, Kattler V, Gess B, Theilig F, Witzgall R, Castrop H: Intravital imaging reveals angiotensin II-induced transcytosis of albumin by podocytes. J Am Soc Nephrol 2016;27:731-744.

52 Schießl IM, Bardehle S, Castrop H: Superficial nephrons in BALB/C and C57BL/6 mice facilitate in vivo multiphoton microscopy of the kidney. PLoS One 2013;8:e52499.

53 Alpers CE, Seifert RA, Hudkins KL, Johnson RJ, Bowen-Pope DF: Developmental patterns of PDGF B-chain, PDGF-receptor, and alphaactin expression in human glomerulogenesis. Kidney Int 1992;42:390-399.

54 Geng H, Lan R, Singha PK, Gilchrist A, Weinreb PH, Violette SM, Weinberg JM, Saikumar $\mathrm{P}$, Venkatachalam MA: Lysophosphatidic acid increases proximal tubule cell secretion of profibrotic cytokines PDGF-B and CTGF through LPA2- and Gaq-mediated rho and av $\beta 6$ integrin-dependent activation of TGF- $\beta$. Am J Pathol 2012;181:1236-1249.

55 Ostendorf T, Kunter U, Gröne HJ, Bahlmann F, Kawachi H, Shimizu F, Koch KM, Janjic N, Floege J: Specific antagonism of PDGF prevents renal scarring in experimental glomerulonephritis. J Am Soc Nephrol 2001;12:909918

56 Tang WW, Ulich TR, Lacey DL, Hill DC, Qi M, Kaufman SA, Van GY, Tarpley JE, Yee JS: Platelet-derived growth factor-BB induces renal tubulointerstitial myofibroblast formation and tubulointerstitial fibrosis. Am J Pathol 1996;148:1169-1180. 